\title{
SEMBLANZA DE PERE GIMFERRER
}

\section{Francisco FERRER LERÍN}

Jaca (Huesca)

\begin{abstract}
$I$ ntensidad es la palabra. La entrada en mi vida de Pedro Gimferrer Torrens produjo una conmoción que se mantuvo durante dos o tres años; actividad frenética diaria sustanciada en la asistencia a las salas de cine y a la visita a librerías y exposiciones.
\end{abstract} Personaje de prodigiosa memoria y exclusiva consagración al mundo de la literatura y las artes, supuso, para mí, la apertura al conocimiento de nuevos autores del universo literario y, también, dada su condición desinhibida, la posibilidad de tratar a la reducida nómina barcelonesa de editores y escritores, a los que Pedro con singular soltura abordaba. Transcribo a continuación algunos textos que hacen mención a la amistad que nos unió durante aquella etapa y al marco en el que se desarrolló la misma. Pedro, El Sabio, Pere y Potencia son los nombres con que se le cita.

(...) Nadie hurtó más y mejor que aquel grupo de poetas caminantes, merodeadores, sabuesos de impar olfato, bibliófilos a la carrera, conocedores de cada una de las librerías de nuevo y de viejo hasta extremos de delirio. (...) Había que explicar el mundo. Y qué mejor manera que encuadrar las cosas en categorías. Eran estas: "Dios" y "Esputo". La primera, por ejemplo, acogía a Orson Welles, a William Faulkner y a Piranesi. La segunda, por ejemplo, acogía a Doris Day, a Gabriel Celaya y a la Jota Navarra. La formulación era la siguiente: "Esto es de Dios" o bien "Esto es un esputo." Teniendo en cuenta que el manejo de estas categorías, aunque no registrado, era de uso casi exclusivo de quien les habla y del poeta conocido por "el Sabio", habrá que reconocer la responsabilidad en que se incurría cada vez que ante las masas sedientas se daba un veredicto. Por lo que no deja de ser sorprendente, desde la actual perspectiva, la inclusión, por parte de "el Sabio", en la categoría de Esputo, yo diría que en su grado máximo, de 
dos conceptos siempre peliagudos como son "lo religioso" y "lo catalán" aunque tal declaración se produjera ante un grupito de exaltados epígonos ávidos de noticias y en un clima de agradable relajación allá en la primavera de $1964 .^{1}$

- ¿Qué tipo de humus había en la Barcelona de la época para el desarrollo de una poesía que dejase atrás el lastre del socialrealismo? ¿Cómo se rompe, en definitiva: hace falta una personalidad muy marcada, unas lecturas muy concretas?

-Barcelona es épater le bourgeois, ir siempre contracorriente (del resto de España). Cursando medicina escribía poemas en inglés, en letra muy gorda, al alcance de mis compañeros de aula; en filología garabateaba cortes anatómicos. Nunca noté presión política; los libros prohibidos se hallaban aún más a mano que los otros: los «infiernos» estaban poco o nada vigilados. ¿Humus? Hijos de la alta burguesía -o al menos dos del cuarteto-, no era necesario soportar el tedio de los celayas y sí indispensable esgrimir nuevas lecturas, a ser posible las más delirantes y qué bien si además albergaban a un genio.

- ¿Cómo se produce -literariamente- el primer contacto entre el grupo: Ferrer Lerín, Gimferrer, Azúa, posteriormente Panero?¿Qué tipo de jerarquía literaria, sobre todo lecturas, se estableció?

-A Pedro -olfateador y lector sin par- le debieron de llegar unos protoversos míos y algún alcahuete organizó la cita, que se materializó durante un festival Antonioni. Félix llegó por la vía lógica del paroxismo elitista. Leopoldo vino de Madrid a pasar unos días y el póquer más que la literatura nos envolvió. La noción de grupo no es la apropiada. A lo más, cuatro tipos unidos por su afición a la carne de ternera. Hubo un careo diario con Pedro que duró dos o tres años con programa cerrado -librerías, galerías de arte, cine-, una relación más laxa con Félix y una relación espasmódica con Leopoldo. Nada de jefes y autoridades; en todo caso algunas recomendaciones por parte de El Sabio en la línea de la obligatoriedad y algunas mías en la línea de la extravagancia. Fruto de todo ello Perse, Borges, Pound, Ossian, Beowulf...

\footnotetext{
${ }^{1}$ Francisco Ferrer Lerín. "Jornada laboral de un poeta barcelonés (1959-1974)”. Ponencia leída en el congreso "Poéticas Novísimas", Zaragoza, 27 de abril de 2002, y publicada en Tropelías, números 15-17, Zaragoza, 2009.
} 
— ¿Cómo se encauzó la acción? ¿Eran solamente tertulias, salidas nocturnas, o había una voluntad de canalizar todo eso en algún tipo de publicación? ¿Crees que eso hubiera sido posible entonces?

-Yo, al menos, no encaucé nada. Como ya se ha dicho no existía la conciencia de grupo y sólo Pedro, en etapas más avanzadas (años de mi mili), a instancias de Castellet por ejemplo, agrupó la tropa y promovió ascensos. En cualquier caso habrá que separar la etapa inicial, en la que estuve presente, de lo que sucedió después. Repito que por lo que a mí respecta nunca pensé en constituir grupos, en dedicarme profesionalmente a aquello y ni siquiera en continuarlo como mero pasatiempo.

- ¿Puede haber ruptura sin conciencia de con qué se está rompiendo ¿Realmente leíais a los poetas precedentes? ¿Quién se salvaba, según vosotros, entonces?

-A algunos de nosotros (y siempre hablo de Pedro, de Félix, en mucha menor medida de Leopoldo y, claro está, de mí, que es de quien únicamente debería hablar) nos llegó antes Henry Miller que Antonio Machado. Para romper hay que estar unido a algo y el nexo con el 98, el 27 y el 50 era inexistente. ¿Hubiera salvado a Cernuda y Lorca? No sé, otros lo hacían por solidaridad corporativa aunque en privado los denostaran; no era mi caso. (...)

- Hablemos de las circunstancias editoriales que rodearon a la aparición de tus libros: ¿a qué puertas llamaste, quién llamó a tu puerta, qué te propusieron incluir, qué decidiste no incluir? ¿Cómo viviste por ejemplo, la publicación de tu primer libro?

-De las condiciones humanas fue editado por Joaquín Buxó Montesinos, poeta y dramaturgo, hijo del marqués de Castellflorit, presidente de la Diputación y de una de las grandes cajas catalanas. Pedro Gimferrer, hombre dotado de un gran desparpajo, al menos en aquellos años, le llamó por teléfono anunciándole que dos poetas irían a verle, y así, en la colección «De trigo y voz provisto» se publicó al poco tiempo... con un tranquilizador prólogo del también poeta Corredor Matheos. La hora oval vino de la mano del poeta Joaquín Marco, abanderado entonces de mi causa y que capitaneaba la colección «Ocnos». Tampoco se consideró apropiado dejarme despegar solo y se bendijo la aventura con un prólogo de Pedro Gimferrer. Cónsul fue el resultado de una selección de poemas, realizada por Félix de Azúa, que por su atrevimiento formal y/o temático habían quedado fuera de La hora oval. Azúa no quiso prologarlo y se pensó esta vez en el poeta catalán Pere Gimferrer. ${ }^{2}$

\footnotetext{
${ }^{2}$ Entrevista publicada en Cuadernos Hispanoamericanos, $n^{\circ}$ 658, Madrid, abril 2005.
} 
(...) De las condiciones humanas estaba abriendo nuevas vías para la expresión poética en España. Era el año 1964, aunque el libro databa en realidad de 1962, y fue publicado, no se olvide, en la misma colección que Mensaje del Tetrarca, de Pedro Gimferrer, de 1963, aunque este último orquestó su presentación en sociedad en fecha suficientemente antedatada. (...) Este verso es también la cita que Gimferrer incluye, junto a otra de Poe, en la primera edición de Mensaje del Tetrarca, publicado en la misma colección. El que el libro de Ferrer Lerín estuviera aún inédito cuando Gimferrer incluye la cita ilustra la proximidad y afinidad de ambos poetas entonces. También lo falaz que resulta hablar de quién fuera en realidad el primero en arribar a qué costas. Pero si la falta de generosidad se pudiera leer como síntoma de miedo pánico a perder la pole position, es notorio que el autor de Arde el mar no incluye los versos de su coevo en sucesivas reediciones de su obra. ${ }^{3}$

(...) de pronto, entre la muchedumbre de barbudos y fumadores en pipa, apartándola gracias a su corpulencia y a su andar vacilante, apareció un personaje de difícil catalogación -joven pero de nobles entradas en una frente rimbombante, rostro incontrolado, cutis jienense, chubasquero de plástico oscuro- que, para mi sorpresa, saludó -eso sí, con altivez- a mis compañeros y se colocó el primero en la más o menos difusa cola. Entramos juntos y tras varios cambios decidió sentarse a mi lado aunque con un espacio de por medio. Encajó su cuerpo en la butaca, y se produjo una especie de terremoto en toda la fila, pero lo sorprendente vino después; al apagarse las lámparas surgió un resplandor, un fogonazo verde, su piel irradiaba una intensa luz, un rarísimo fenómeno de fosforescencia que (...) es la causa, junto a otras, por la que le denominaremos Potencia, evitando también con esta triquiñuela cualquier tipo de responsabilidad, ya que hoy es persona de poder omnímodo. (...) su prodigiosa memoria que según parece hacía que los profesores acudieran a él y, luego, las sempiternas manchas en sus pantalones bombachos producidas por la sardina de lata en aceite envuelta en papel de periódico que se traía de casa y que hasta ser consumida en el recreo permanecía en sus bolsillos (alternaba derecho e izquierdo). (...) era un ser omnipresente, era tiránico en sus obsesiones intelectuales y, a su desaliño corporal, sumaba una dificultad motriz estrepitosa. Dos ejemplos sobre esto último: no sólo no acertaba nunca

\footnotetext{
${ }^{3}$ Carlos Jiménez Arribas, «Prólogo», en F. Ferrer Lerín, Ciudad propia. Poesía autorizada, Artemisa Ediciones, Tenerife, 2006.
} 
a entrar por una puerta -se golpeaba contra el marco- sino que era incapaz de sujetar cualquier objeto y así se llegaba a situaciones insostenibles como en aquel cóctel en la Terraza Martini (a menudo nos colábamos en eventos así) en que fue expulsado tras habérsele escapado de la mano un vaso de whisky -que estalló con gran estrépito al chocar contra la barra- luego derramar una copa de champán en la moqueta y, finalmente, esparcir por los peldaños de la escalera todos los canapés de una bandeja durante el forcejeo con un camarero creyendo que éste se la ofrecía entera. Pero no había rivalidad entre nosotros. Potencia vivía en el mundo de la fantasía. Y yo en el de la realidad. En el momento en que el grado de compenetración fue lo suficientemente elevado y no fueron necesarias las farragosas preguntas, sólo diciendo Miller le refería cuáles habían sido mis últimos lances sexuales y, si decía Rossen, le contaba el resultado de la timba de anoche. Porque los libros y el cine -y las artes plásticas secundariamente- ocupaban en exclusiva nuestro marco de relación pero él vivía dentro de ellos y yo, en cambio, me limitaba a disfrutar con ellos, como disfrutaba también con otras cosas. (...) Tras ver El buscavidas y llegar a la conclusión de que era el único epílogo posible del cine negro emprendimos una tournée por las salas de billar. Potencia era el Gordo de Minnesota y yo era Paul Newman. En una de ellas, creo que en "El velódromo", un hombrecillo pulcro que por allí trotaba nos estuvo estudiando largo rato -Potencia de Minnesota con traje oscuro sentado en una silla con las regordetas piernas abiertas y Paul Amatller inclinado sobre la mesa dándole al taco y a las bolas- y debió parecerle un cuadro de gran carga sexual porque nos abordó resuelto, y nos propuso hacer lo mismo en su casa pero todos con menos ropa y con algún dinero a cambio. ${ }^{4}$

\footnotetext{
${ }^{4}$ F. Ferrer Lerín, Familias como la mía, Tusquets Editores, Barcelona, 2011.
} 